\title{
PENGARUH KOMORBIDITAS DAN RIWAYAT SEKSIO SESARIA TERHADAP PERSALINAN SEKSIO SESARIA DI RSUD TARAKAN
}

\author{
Ika Yulianti ${ }^{1)}$, Rahmi Padlillah ${ }^{2)}$, Gusriani $^{3)}$ \\ 1,2,\&3 Jurusan Kebidanan Fakultas Ilmu Kesehatan, Universitas Borneo Tarakan \\ Email: ikatamaevan@gmail.com
}

\begin{abstract}
Abstrak
Latar Belakang: Prevalensi kejadian persalinan seksio sesaria terus mengalami peningkatan. Komorbiditas dan riwayat seksio sesaria adalah faktor risiko terjadinya persalinan seksio sesaria, sehingga diperlukan penelitian yang relevan untuk mengkaji faktor komorbiditas dan riwayat seksio sesaria terhadap kejadian persalinan seksio sesaria yang dilakukan di RSUD Tarakan. Tujuan: Mengetahui pengaruh komorbiditas dan riwayat seksio sesaria terhadap persalinan seksio sesaria. Metode:Jenis penelitian adalah penelitian kuantitatif dengan desain penelitian menggunakan kasus kontrol, jumlah responden 250 sampel, dipilih secara purposive sampling yang dianalisis dengan regresi logistic. Hasil: Uji regresi logistik menunjukkan pengaruh komorbiditas terhadap persalinan seksio sesaria dengan $p<0,001$ dan pengaruh riwayat seksio sesaria terhadap persalinan seksio sesaria dengan $p<0,001$. Kesimpulan: ada pengaruh komorbiditas dan riwayat persalinan seksio sesaria terhadap persalinan seksio sesaria di RSUD Tarakan.
\end{abstract}

Kata Kunci: Komorbiditas, Riwayat Seksio Sesaria, Persalinan Seksio Sesaria

\begin{abstract}
Effect of comorbidities and history of cesarean section on cesarean at Tarakan Hospital. Background: The prevalence of childbirth seksio sesaria continues to increase. Comorbidity and history of sesaria sectio is a risk factor for the occurrence of childbirth seksio sesaria, so relevant research is needed to examine the comorbidity factors and history of sesaria sectio to the incidence of childbirth seksio sesaria conducted at Tarakan Hospital. Purpose: To know the effect of comorbidity and history of sesaria sectio on childbirth seksio sesaria. Method: This type of research is quantitative research with research design using control case, number of respondents 200 samples, selected by purposive sampling analyzed with logistic regression. Result: Logistic regression test showed the effect of comorbidity on childbirth seksio sesaria with $p<0.001$ and the influence history of of sesaria sectio on childbirth seksio sesaria with $p<0,001$. Conclusion: there is an influence of comorbidity and history of sesaria sectio childbirth on seksio sesaria in Tarakan Hospital.
\end{abstract}

Keywords: Comorbidity, History of Sesaria Sectio, Childbirth Seksio Sesaria 


\section{Pendahuluan}

Penatalaksanaan persalinan yang buruk secara global menyebabkan 300.000 kematian ibu pada saat proses persalinan. 99\% Angka Kematian Ibu (AKI) berasal dari negara dengan ekonomi rendah dan menengah (Kemenkes RI, 2014). AKI di Indonesia berdasarkan Survei Demografi dan Kesehatan Indonesia tahun 2012 masih tinggi yaitu sebesar 359 per 100.000 kelahiran hidup. Pencapaian tersebut masih jauh dari target MDGs (Millenium Development Goals) ke-5 yaitu menurunkan AKI menjadi 70 per 100000 kelahiran hidup.

Penatalaksanaan persalinan pervaginam dan seksio sesaria yang baik adalah upaya untuk menurunkan AKI dan AKB (WHO, 2015). Persalinan seksio sesaria (SC) adalah penatalaksanaan persalinan dengan jalan operasi dalam dunia kebidanan dengan insiden yang terus meningkat di seluruh dunia. (Vogel et al., 2015). 10 hingga 25\% variasi terjadinya persalinan seksio sesaria di negara berkembang dengan angka morbiditas dan mortalitas pada ibu dan janin dilaporkan meningkat mengikuti peningkatan tindakan CS jika dibandingkan dengan persalinan pervaginam (Diana and Tipandjan, 2016)

Evaluasi yang komprehensif terkait data faktor-faktor yang mempengaruhi komplikasi pada persalinan seksio sesaria yang ada diperlukan untuk menetapkan tindakan yang tepat untuk mencegah AKI dan AKB setelah persalinan dengan seksio sesaria serta untuk merencanakan program dan mengalokasikan sumber daya untuk persalinan seksio sesaria yang aman (Keag et al., 2018).

Oliveira et al. (2016) menjelaskan bahwa faktor yang berhubungan dengan persalinan seksio sesaria adalah riwayat persalinan SC kelebihan berat badan/obesitas dan pendapatan keluarga dan komorbiditas. Banyak faktor yang telah memberikan kontribusi terhadap meningkatnya persalinan seksio sesaria termasuk faktor medis dan nonmedis sehingga perlu mendapatkan perhatian dan penelitian terkait faktor yang berpengaruh terhadap persalinan seksio sesaria untuk menurunkan persalinan seksio sesaria. Berdasarkan latar belakang permasalahan tersebut peneliti tertarik untuk menganalisis "pengaruh komorbiditas dan riwayat seksio sesaria terhadap persalinan seksio sesaria di RSUD Tarakan".

Komorbiditas merupakan penyakit penyerta yang menyertai pada kehamilan sehingga dapat menimbulkan komplikasi selama proses persalinan seksio sesaria (Wulandari et al., 2018). Penyakit yang sudah ada sebelumnya pada ibu meningkatkan probabilitas faktor risiko yang dapat memerlukan persalinan seksio sesaria seperti hipertensi dan diabetes mellitus atau kehamilan diabetes yang jika tidak diobati dapat mengakibatkan kelahiran anak dengan bobot lahir lebih dari 4000 gram (makrosomia). Makrosomia janin dianggap sebagai indikasi relatif untuk dilakukan persalinan seksio sesaria (Walfisch et al., 2014). 
Kormobiditas pada persalinan seksio sesaria dikaitkan dengan hipertensi yang menyebabkan eklamsia, diabetes yang berisiko terjadinya makrosomia dan HIV terkait pencegahan penulatannya terhadap bayi yang dilahirkan ataupun penyakit kronik lainnya yang tidak memungkinkan untuk persalinan secara pervaginam. Hasil penelitian menunjukkan bahwa preeklamsia berhubungan dengan persalinan seksio sesaria dengan nilai $\mathrm{OR}=1.44$ berarti ibu dengan preeklamsia memiliki probabilitas untuk persalinan seksio sesaria 1.44 kali lebih besar dibangdingkan dengan ibu hamil non komorbiditas preeklamsia (Kawakita, 2016).

Hipertensi, asma, diabetes mellitus, preeklamsia merupakan beberapa penyakit yang dapat menjadi penyakit penyerta atau kemorbiditas dalam persalinan seksio sesaria (Andayasari et al., 2015). Kunjungan ANC yang kurang menyebabkan deteksi dini terkait indikasi persalinan seksio sesaria kurang, risiko terjadi penyakit selama kehamilan misalnya hipertensi, anemia, diabetes dan penyakit kronik lainnya karena ibu tidak melakukan pencegahan selama masa kehamilan disebabkan pengetahuan yang kurang akan pentingnya pencegahan kompikasi penyakit yang terjadi selama masa kehamilan sehingga kurangnya deteksi dini (Benzouina et al., 2016).

Mortalitas pada persalinan seksario meningkat karena adanya komorbiditas. $1.4 \%$ kasus rujukan persalinan karena adanya komplikasi terkait komorbiditas sehingga harus segera dilakukan persalinan seksio sesaria, diperlukan upaya deteksi dini untuk menurunkan angka morbiditas pada persalinan seksio sesaria. Penelitian ini bertujuan untuk pengaruh komorbiditas terhadap persalinan seksio sesaria.

\section{Landasan Teori}

Tabel 1. Komplikasi persalinan seksio sesaria

\begin{tabular}{lc}
\hline \multicolumn{1}{c}{ Kriteria } & \multicolumn{1}{c}{ Komplikasi } \\
\hline $\begin{array}{c}\text { Komplikasi } \\
\text { intraoperatif }\end{array}$ & Infeksi \\
& $\begin{array}{c}\text { Kerusakan organ } \\
\text { (kandung kemih, usus, } \\
\text { ureter dan lainnya) }\end{array}$ \\
Komplikasi & Kebutuhan tranfusi darah \\
postoperatif & Histerektomi \\
& Thromboembolic \\
& Nyeri berat \\
& Retardasi \\
Komplikasi & pertumbuhan \\
kehamilan & Persalinan prematur \\
selanjutnya & Aborsi spontan \\
& Kehamilan ektopik \\
& Infertilitas \\
\hline
\end{tabular}

Sumber : Mylonas dan Friese (2015)

\section{Metode}

Jenis penelitian dalam penelitian ini adalah penelitian kuanitatif dengan pendekatan kasus kontrol. Metode pengumpulan data menggunakan lembar tabulasi karena dalam penelitian ini menggunakan data sekunder. Populasi penelitian adalah ibu bersalin secara normal dan seksio sesaria berdasarkan data penelitian tahun 2020.

Teknik sampling dalam penelitian ini menggunakan purposive sampling dengan kriteria inklusi adalah sampel atau responden yang berada dalam kuru waktu penelitian sesuai dengan data sekunder di RSUD 
Tarakan serta data yang dibutuhkan baik variabel bebas dan terikat terpenuhi dengan baik/ jelas. Kriteria ekslusi data sampel tidak lengkap. Uji statistik menggunakan analisis regresi logistik.

\section{Hasil}

\section{Karakteristik Responden}

a. Umur

Karakteristik umum dalam penelitian ini adalah umur, analisis univariat digunakan untuk mengetahui distribusi frekuensi umur.

Tabel 2. Distribusi frekuensi karakteristik umur pada ibu bersalin di RSUD Tarakan

\begin{tabular}{lcc}
\hline Umur & n & \% \\
\hline 20 - 35 tahun & 106 & 42,4 \\
\hline$<20$ dan $\geq 35$ tahun & 144 & 57,6 \\
\hline Total & 250 & 100 \\
\hline
\end{tabular}

Sumber: Data Sekunder

Berdasarkan tabel 2 menunjukkan bahwa sebagian besar responden memiliki umur $<20$ tahun dan $\geq 35$ tahun yaitu sebanyak 144 responden atau sebesar 57,6\% . b. Paritas

Karakteristik paritas dalam penelitian ini adalah paritas, analisis univariat digunakan untuk mengetahui distribusi frekuensi umur.

Tabel 3. Distribusi frekuensi karakteristik paritas pada ibu bersalin di RSUD Tarakan

\begin{tabular}{lcc}
\hline Paritas & n & \% \\
\hline Primipara & 126 & 50,4 \\
\hline Multipara & 124 & 49,6 \\
\hline Total & 250 & 100 \\
\hline
\end{tabular}

Sumber: Data Sekunder

Berdasarkan tabel 3 menunjukkan bahwa sebagian besar responden dengan paritas primipara yaitu sebanyak 126 responden atau sebesar $50,4 \%$. c. Riwayat Seksio Sesaria

Variabel independen dalam penelitian ini adalah riwayat seksio sesaria, secara univariat dilakukan untuk melihat distribusi frekuensi data .

Tabel 4. Distribusi frekuensi karakteristik paritas pada ibu bersalin di RSUD Tarakan

\begin{tabular}{lcc} 
Paritas & n & \% \\
\hline Tidak Ada & 179 & 71,6 \\
\hline Ada & 71 & 28,4 \\
\hline Total & 250 & 100 \\
\hline
\end{tabular}

Sumber: Data Sekunder

Berdasarkan tabel 4 menunjukkan bahwa sebagian besar responden tidak ada riwayat seksio sesaria yaitu sebanyak 179 responden atau sebesar $71,6 \%$.

d. Komorbiditas

Variabel independen dalam penelitian ini adalah komorbiditas, secara univariat dilakukan untuk melihat distribusi frekuensi data.

Tabel 5. Distribusi frekuensi karakteristik komorbiditas pada ibu bersalin di RSUD Tarakan

\begin{tabular}{lcc}
\hline Komorbiditas & n & \% \\
\hline Tidak Memiliki & 123 & 49,2 \\
\hline Memiliki & 127 & 50,8 \\
\hline Total & 250 & 100 \\
\hline
\end{tabular}

Sumber: Data Sekunder

Berdasarkan tabel 5 menunjukkan bahwa sebagian besar responden memiliki komorbiditas yaitu sebanyak 127 responden atau sebesar $50,8 \%$.

e. Persalinan Seksio Sesaria

Variabel dependen dalam penelitian ini adalah persalinan seksio sesaria, secara univariat dilakukan untuk melihat distribusi frekuensi data. 
Tabel 6. Distribusi frekuensi karakteristik persalinan seksio sesaria pada ibu bersalin di RSUD Tarakan

\begin{tabular}{lcll}
\hline Persalinan Seksio Sesaria & n & \% \\
\hline Persalinan Normal & 100 & 40 & \\
\hline Persalinan Seksio Sesaria & 150 & 60 \\
\hline Total & 250 & 100 \\
\hline
\end{tabular}

Sumber: Data Sekunder

Berdasarkan tabel 4.5 menunjukkan bahwa

persalinan seksio sesaria yaitu sebanyak 150 sebagian besar responden melakukan responden atau sebesar $60 \%$.

\section{Analisis Bivariat}

Tabel 7. Analisis Bivariat Hubungan Komorbiditas dan Riwayat Seksio Sesaria dengan Persalinan Seksio Sesaria

\begin{tabular}{|c|c|c|c|c|c|c|c|c|}
\hline \multirow{3}{*}{$\begin{array}{c}\text { Kelompok } \\
\text { Variabel }\end{array}$} & \multicolumn{4}{|c|}{ Persalinan Seksio Sesaria } & \multirow{2}{*}{\multicolumn{2}{|c|}{ Total }} & \multirow{3}{*}{ OR } & \multirow{3}{*}{$\mathbf{p}$} \\
\hline & \multicolumn{2}{|c|}{ Normal } & \multicolumn{2}{|c|}{ SC } & & & & \\
\hline & $\mathbf{N}$ & $\%$ & $\mathbf{N}$ & $\%$ & $\mathbf{N}$ & $\%$ & & \\
\hline Komorbiditas & & & & & & & & \\
\hline Tidak Memiliki & 71 & 57,7 & 52 & 42,3 & 123 & 100 & 4,61 & $<0,001$ \\
\hline Memiliki & 29 & 22,8 & 98 & 77,2 & 127 & 100 & & \\
\hline $\begin{array}{c}\text { Riwayat Seksio } \\
\text { Sesaria }\end{array}$ & & & & & & & & \\
\hline Tidak Ada & 93 & 52 & 86 & 48 & 179 & 100 & 9,89 & $<0,001$ \\
\hline Ada & 7 & 9,9 & 64 & 90,1 & 71 & 100 & & \\
\hline
\end{tabular}

Sumber: Data Sekunder

Berdasarkan Tabel 7. menunjukkan bahwa analisis hubungan antara komorbiditas dan persalinan seksio sesaria dengan nilai $\mathrm{p}<$ 0.001 dan $\mathrm{OR}=4,61$, sehingga dapat diinterpretasikan bahwa ada hubungan yang signifikan. Ibu bersalin yang komorbiditas memiliki kemungkinan 4,61 kali untuk melakukan persalinan seksio sesaria dibandingkan dengan ibu bersalin yang tidak memiliki komorbiditas.

\section{a. Analisis Regresi Logistik}

Analisis multivariat dilakukan dengan uji statistic yang menggunakan uji regresi logisik untuk mengetahui adanya pengaruh komorbiditas dan riwayat seksio sesaria
Berdasarkan Tabel 7. menunjukkan bahwa analisis hubungan antara riwayat persalinan seksio sesaria dan persalinan seksio sesaria dengan nilai $\mathrm{p}<0.001$ dan $\mathrm{OR}=$ 9,89, sehingga dapat diinterpretasikan bahwa ada hubungan yang signifikan. Ibu bersalin yang ada riwayat seksio sesaria memiliki kemungkinan 9,89 kali untuk melakukan persalinan seksio sesaria dibandingkan dengan ibu bersalin yang tidak ada riwayat persalinan seksio sesaria.

terhadap persalinan seksio sesaria. Hasil uji regresi logistik ditunjukkan oleh table 7 . dengan rincian sebagai berikut: 
Tabel 8. Analisis Pengaruh Komorbiditas dan Riwayat Seksio Sesaria terhadap Persalinan Seksio Sesaria

\begin{tabular}{lcccc}
\hline \multirow{2}{*}{\begin{tabular}{l} 
Persalinan Seksio Sesaria \\
\cline { 3 - 4 }
\end{tabular}} & OR & $\begin{array}{c}\text { CI 95\% } \\
\text { Batas }\end{array}$ & $\begin{array}{c}\text { Batas } \\
\text { Atas }\end{array}$ & P \\
\hline Komorbiditas & 2,32 & 4,29 & 24,30 & $<0,001$ \\
Riwayat Seksio Sesaria & 1,56 & 2,63 & 8,63 & $<0,001$ \\
\hline
\end{tabular}

Sumber: Data Sekunder

Hasil analisis multivariat menunjukkan ada pengaruh komorbiditas terhadap persalinan seksio sesaria. Ibu dengan komorbiditas memiliki kemungkinan untuk menggunakan persalinan seksio sesaria $(\mathrm{OR}=2,32 ; 95 \% \mathrm{CI}=4,29-24,30 ; \mathrm{p}<0.001)$.

Hasil analisis multivariat menunjukkan ada pengaruh riwayat persalinan seksio sesaria terhadap persalinan seksio sesaria. Ibu dengan riwayat persalinan seksio sesaria memiliki kemungkinan untuk menggunakan persalinan seksio sesaria $(\mathrm{OR}=1,56 ; 95 \%$ $\mathrm{CI}=2,63-8,63 ; \mathrm{p}<0.001)$.

\section{Pembahasan}

\section{Pengaruh komorbiditas terhadap persalinan seksio sesaria}

Berdasarkan hasil penelitian menunjukkan bahwa ada pengaruh komorbiditas terhadap persalinan seksio sesaria. Hasil penelitian tersebut sejalan dengan studi Wang et al., (2018) yang menunjukkan bahwa pasien yang melakukan persalinan seksio sesaria adalah pasien dengan indikasi medis atau memiliki penyakit klinis, seperti hipertensi, diabetes mellitus, asma, selain iu ada patologi rahim seperti adenomiosis, mioma dan kondisi lainnya.

Faktor yang mempengaruhi persalinan seksio sesaria khususnya pada faktor komorbiditas merupakan faktor yang harus di deteksi dini sehingga persalinan seksio sesaria dilakukan sesuai indikasi. Oliveira et al. (2016) menjelaskan bahwa faktor yang berhubungan dengan persalinan seksio sesaria adalah komorbiditas yang secara statistik berhubungan dengan arah hubungan yang positif dengan hasil penelitian $(\mathrm{OR}=3,38, \mathrm{p}=$ 0.017), artinya ibu yang memiliki komorbiditas memiliki kemungkinan 3,38 kali lebih besar untuk terjadinya persalinan seksio sesaria dibandingkan dengan ibu yang tidak memiliki komorbiditas.

Hasil penelitian lainnya juga menunjukkan bahwa preeklamsia sebagai salah satu komorbiditas berhubungan dengan persalinan seksio sesaria dengan nilai $\mathrm{OR}=$ 1.44 berarti ibu dengan preeklamsia memiliki probabilitas untuk persalinan seksio sesaria 1.44 kali lebih besar dibangdingkan dengan ibu hamil non komorbiditas preeklamsia (Kawakita, 2016). Diabetes mellitus atau kehamilan diabetes yang jika tidak diobati juga dapat menjadi komorbiditas pada persalinan seksio sesaria diabetes mellitus mengakibatkan kelahiran anak dengan bobot lahir lebih dari 4000 gram (makrosomia). Makrosomia janin dianggap sebagai indikasi relative untuk dilakukan persalinan seksio sesaria (Walfisch et al., 2018). 


\section{Pengaruh riwayat seksio sesaria} terhadap persalinan seksio sesaria

Hasil penelitian menunjukkan bahwa ada pengaruh riwayat seksio sesaria terhadap persalinan seksio sesaria. Hasil penelitian tersebut sejalan dengan studi Wu et al. (2018) yang menyebutan bahwa ada riwayat seksio sesaria pada persalinan sebelumnya merupakan salah satu faktor risiko yang berpengaruh terhadap terjadinya persalinan seksio sesaria. Ibu dengan riwayat seksio sesaria yang kurang dari 2 tahun memiliki risiko yang lebih besar untuk terjadinya persalinan seksio sesaria dibandingkan dengan ibu yang lebih dari 2 tahun karena kondisi Rahim yang belum pulih dan berfungsi secara optimal sehingga berisiko lebih besar. Oliveira et al. (2016) menjelaskan bahwa salah satu determinan faktor yang mempengaruhi persalinan seksio sesaria adalah riwayat persalinan $\mathrm{SC}(\mathrm{OR}=11,11, \mathrm{p}=$ 0.028), sehingga ibu dengan riwayat seksio sesaria memiliki kemungkinan 11,11 kali lebih besar untuk terjadinya seksio sesaria dibandingkan dengan ibu yang tidak ada riwayat seksio sesaria. Dengan demikian dapat dilakukan asuhan yang sesuai dan tepat dengan keadaan ibu untuk deteksi dini sebagai upaya preventif dan represif pada layanan antenatal care pada ibu hamil dengan indikasi seksio sesaria.

Sunanda dan Ranganth (2016) menjelaskan bahwa indikasi relatif persalinan seksio sesaria salah satunya adalah riwayat persalinan seksio sesaria sebelumnya, selain itu presentasi bokong, distosia bahu yang juga dapat disebabkan karena terjadinya makrosomia pada janin sehingga meningkatkan risiko komplikasi kebidanan yang bertanggung jawab atas terjadinya morbiditas parah pada neonatal serta fetal distress juga sebagai indikasi relatif persalinan seksio sesaria.

\section{Kesimpulan}

Hasil penelitian menunjukkan bahwa ada pengaruh komorbiditas terhadap persalinan seksio sesaria. Ibu dengan komorbiditas memiliki kemungkinan 2,32 kali untuk menggunakan persalinan seksio sesaria dan secara statistik signifikan.).

Ada pengaruh riwayat persalinan seksio sesaria terhadap persalinan seksio sesaria. Ibu dengan riwayat persalinan seksio sesaria memiliki kemungkinan 1,56 kali untuk menggunakan persalinan seksio sesaria dan secara statistik signifikan.

\section{Referensi}

Andayasari L, Muljati S, Sihombing M, Arlinda D, Opitasari C, Mogsa DF, Widianto. (2015). Proporsi seksio sesaria dan faktor yang berhubungan dengan seksio sesaria di Jakarta. Buletin Penelitian Kesehatan, 43(2): 105-116.

Benzouina S, Boubkraoui MEM, Mrabet M, Chahid N, Kharbach A, El-Hassani A, et al. Fetal outcome in emergency versus elective cesarean sections at Souissi Maternity Hospital, Rabat, Morocco. Pan Afr Med J. 2016;23:197. Diana, V. and Tipandjan, A. (2016) 'Emergency and elective caesarean sections: comparison of maternal and fetal outcomes in a suburban tertiary 
care hospital in Puducherry', International Journal of Reproduction, Contraception, Obstetrics and Gynecology, 5(9), pp. 3060-3065.

Kawakita. Adverse maternal and neonatal outcomes in adolescent pregnancy. JAMA J Am Med Assoc. 2016;29(2):130-6.

Keag OE, Norman JE, Stock SJ. (2018). Long-term risks and benefits associated with cesarean delivery for mother, baby, and subsequent pregnancies: Systematic review and meta-analysis. PLoS Med.15(1):1-22.

Kemenkes RI. Mother's day. Vol. 33, Kenyon Review. 2014. p. 4-19.

Mulyawati, Isti. (2011). Faktor- Faktor yang berhubungan dengan persalinan operasi seksio sesarea di Rumah Sakit Islam YAKSSI Gemolong Kabupaten Sragen. Skripsi. Universitas Negeri Semarang.

Mylonas I, Friese K. Indikationen, Vorzüge und Risiken einer elektiven Kaiserschnittoperation. Dtsch Arztebl Int. 2015;112(29-30):489-95.

Oliveira RR, Melo EC, Novaes ES, Ferracioli PLRV, Mathias TA de F. Factors associated to Caesarean delivery in public and private health care systems. Rev da Esc Enferm. 2016;50(5):73340.

Santas G, Santas F. Trends of caesarean section rates in Turkey. $\mathrm{J}$ Obstet Gynaecol (Lahore) [Internet]. 2018;38(5):658-62. Available from: https://doi.org/10.1080/01443615.201 7.1400525.

Sunanda N., dan Ranganth P. A. A two year analysis of uterine rupture in pregnancy. Int J Reprod Contracept Obstet Gynecol. 2016; 5(11). 3983-6. (2016).

Syaifuddin Ali Akhmad. 2008. Panduan Lengkap Kehamilan, Persalinan, dan Perawatan Bayi. Jogjakarta: DIGLOSSIA MEDIA.

Vogel, J. P. et al. (2015) 'Use of the robson classification to assess caesarean section trends in 21 countries: A secondary analysis of two WHO multicountry surveys', The Lancet Global Health.

Walfisch A, Beloosesky R, Shrim A, Hallak M. Adhesion prevention after cesarean delivery: Evidence, and lack of it. Am $\mathrm{J}$ Obstet Gynecol [Internet]. 2014;211(5):446-52. Available from: http://dx.doi.org/10.1016/j.ajog.2014. 05.027.

Wang C.P., Tan W.C., Kanagalingam D., Tan H.K. Why we do caesars: a comparison of the trends in caesarean section delivery over a decade. Ann Acad Med Singapore. 2018;42(8):408-412.

WHO. Caesarean section rates. Lancet. 2015;342(8885):1490.

Wulandari P, Maharani RP, Arifianto. (2018). Faktor - faktor yang berhubungan tindakan persalinan seksio sesaria di rumah sakit Santa Elisabeth Semarang. JHNS, 5(2).

Wu Y, Wang Y, Huang J, Zhang Z, Wang J, Zhou $\mathrm{L}$, et al. The Association Between Caesarean Delivery and the Initiation and Duration of Breastfeeding: a Prospective Cohort Study in China. Eur J Clin Nutr. 2018;72(12):1644-54. 